\title{
EML4/ALK Fusion Protein Variant 2
}

National Cancer Institute

\section{Source}

National Cancer Institute. EML4/ALK Fusion Protein Variant 2. NCI Thesaurus. Code C99735.

A fusion protein (1310 aa, 146 kDa) that is encoded by the EML4/ALK variant 2 fusion gene. This protein is comprised of the most of the echinoderm microtubule-associated protein-like 4 fused to the entire cytoplasmic domain of the ALK tyrosine kinase receptor protein including the tyrosine kinase domain. 